\title{
Design, Development and Evaluation of a Small Scale Kitchen Waste Composting Machine
}

\author{
IjagbemiChristiana.O ${ }^{\mathrm{a}}$, Adepo S. Olusegun ${ }^{\mathrm{b}}$ \\ ${ }^{a}$ Department of Mechanical Engineering, Federal University of Technology, Akure, Nigeria \\ ${ }^{\mathrm{b}}$ Department of Mechanical Engineering Technology, Rufus Giwa Polytechnic, Owo, Nigeria
}

\begin{abstract}
The huge cost incurred in the packing and transportation of domestic waste in Nigeria accounts for not less than $60 \%$ of the total budget for waste management. The design of a cost effective composting machine for small-scale production of manure (compost) from kitchen wastes is achieved. Actual efficiency of $64.09 \%$ was recorded as compared to the theoretical efficiency of $80 \%$.
\end{abstract}

Keywords: - Composting, Kitchen Wastes, Efficiency, Recycling

\section{INTRODUCTION}

As families and communities search for safe and effective ways to manage kitchen wastes, compostingbecomes a more attractive management option, this not onlyrestore value to it but also lead to a reduction in the amount of waste that require disposal. Although informal recycling activities of waste materials is wide spread in developing countries, the treatment and use of biodegradable organic fraction, especially for kitchen waste, is still fairly limited. Increasingly, international and municipal authorities now look at new ways to manage their organic solid waste through the introduction of compost plants (in developing countries) which is an excellent way to avoid wasting useful, natural resources and also avoid creating environmental problems, while at the same time producing a high quality and inexpensive soil amendment (Rynk, 1999). The first industrial station for the transformation of urban organic materials into compost was set up in Austria in the year 1926 (Ellis, 2000).Composting is the biological process of breaking up of organic waste such as kitchen waste, manure, leaves, grass trimmings, worms, and coffee grounds, etc, into an extremely useful humus-like substance by various micro-organisms including bacteria, fungi and actinomycetes in the presence of oxygen (Wilson, 2009). Composting is the biological degradation of organic substrates aerobically or anaerobically under conditions of temperature and moisture suitable for acting micro-organisms to thrive, with a final product stable for storage and application to soil without adverse environment environmental impact.

\section{DESIGN}

\subsection{Design Considerations}

Design factors such as availability of component parts, ease of machinability, affordability, efficiency and ease of operation were considered in the design of the kitchen waste composting machine.

\subsection{Design Description}

The composting machine consists of a composting drum made from galvanized steel, and is enclosed by an outer cylinder mounted directly on a frame. A feeding hopper enters from outside through the cylindrical enclosure into the composting drum. The cylinders, both inner and outer, are designed together such that there is a vacuum between them. The outer cylinder bears a box together such that there is a vacuum between them. The outer cylinder bears a box on one of its sides. This box houses a heating coil and a fan mounted just behind it. Perforations are created through the outer cylinder on the side which is attached to the box. Heat is produced by an electrically controlled heating coil, regulated by a thermostat, which warms up the air in the box, together with air coming from outside through an opening created at the back of the box. The fan drives the heated air in a desired direction (through the perforations) into the vacuum between the inner and the outer cylinders. This heated air, by means of convention heat transfer, warms up the inner cylinder/composting drum in which the waste materials to be composted are stored in order to achieve a slow drying of the materials to be composted are stored in order to achieve a slow drying of the materials. A $30 \mathrm{~mm}$ diameter shaft passing through the center of the composting drum horizontally and spans through the length of the composting drum inside, on which a masher having its design like that of a worm conveyor is mounted, is being driven by a $2.5 \mathrm{HP}$ geared motor with an average output speed of 60rpm. The masher does the task of mashing the waste materials against the inner walls of the composting cylinder. Simultaneously, the mashing, mixing and the low-heat addition (drying) processes occur over a period toachieve the desired result. 


\subsubsection{Composting Drum}

The composting drum is a small sized cylindrical-shaped hollow solid made of galvanized steel pipe of $300 \mathrm{~mm}$ diameter and a length of $500 \mathrm{~mm}$. it is the major container of the waste materials, and it houses the masher with its shaft.

The composting drum's total volume is given by:

$V=\pi r^{2} l$

Where,

$V=$ volume of the drum

$r=$ inner radius of the drum

$l=$ total length of the drum

Inner radius $r=\frac{300}{2}=150 \mathrm{~mm}$

Total length $l=500 \mathrm{~mm}$

Volume $=\pi \times 150^{2} \times 500=35,342,917.3 \mathrm{~mm}^{3}$

\subsubsection{Masher Assembly Design}

$\mathrm{B}=$ Axial distance between mashers $=65 \mathrm{~mm}$

$\mathrm{T}=$ Tolerance between drum and first mesh $=15 \mathrm{~mm}$

$\mathrm{W}=$ Distance of flight perpendicular to flight

$$
\frac{B}{\operatorname{Cos} \phi}+T
$$

$\varnothing=$ helix angle $=15^{\circ}$

Masher Thickness $=\frac{(\text { leng htofinnerdrum }-w)}{(\text { Noofmas hers }}$

Volume of masher $=\frac{1}{3} \pi r^{2} T$

for 5 mashing surfaces, volume $=\mathrm{V} \times 5$

Mass of masher $=$ density $\mathrm{x}$ volume

\subsubsection{Shaft Diameter}

$$
\text { forceperunitlenght }=\frac{\text { force }}{\text { totallenght }}
$$

The diameter of the shaft is given by the equation:

$\mathrm{d}^{3}=16 / \pi(\mathrm{Ss} \sqrt{\mathrm{M}} b \times \mathrm{K} b)^{2} \times(\mathrm{M} t \times \mathrm{K} t)^{2}$

Where,

$\mathrm{M} b=22.84 \mathrm{Nm}$

$\mathrm{M} t=$ maximum torsion moment, $324 \mathrm{Nm}$ (calculated)

$\mathrm{K} b=$ combine shock and fatigue applied to bending, 1.5

$\mathrm{Kt}=$ combine shock and fatigue applied to torsion, 1.0

Ss $=$ allowable shear stress for shaft with keyways, $40 \mathrm{MPa}$ or $40 \times 10^{6}$

Using a factor of safety of 0.9

Thus, a shaft of $30 \mathrm{~mm}$ is selected.

\subsubsection{Shaft Key Design}

The shaft key is maximum allowable shear stress.

Width of key, $w=d / 4$

Thickness of key, $\mathrm{t}=\frac{2 w}{3}$

Where,

$\mathrm{d}=$ inner diameter of the shaft to be selected, $30 \mathrm{~mm}$

\subsubsection{Maximum Volume of Food Waste}

Maximum volume of food waste that can be composted at a time is given by

$V_{A}=V_{D}-V_{M}$

Where,

$V_{A}=$ Actual volume of inner cylindrical drum

$V_{D}=$ Volume of inner cylindrical drum $=0.035 \mathrm{~m}^{3}$

$V_{M}=$ Volume of mashers

\subsubsection{Design for the Gear}

The minimum number of teeth on the pinion, $\mathrm{Tp}$, in order to avoid interference is given by:

$$
T p=\frac{2 A W}{G}\left(\sqrt{1}+G\left(\frac{1}{G}+2\right) \sin ^{2} \phi-1\right)
$$


(Khurmi and Gupta, 2005)

Where,

$T p=$ minimum number of teeth on the pinion

$\mathrm{A}_{\mathrm{w}}=$ fraction by which standard addendum

$\mathrm{G}=$ gear ratio or velocity ratio

$\mathrm{G}=\frac{T g}{T p}=\frac{D g}{D p}$

$\varnothing=$ pressure angle

The tangential load can be used to obtain the power transmitted using the pitch velocity.

$\mathrm{W}_{\mathrm{T}}=\left(\frac{P}{V}\right) \times \mathrm{Cs}$

Where,

$\mathrm{P}=$ Power transmitted in watts

$\mathrm{Cs}=$ Service factor, which is 1.25 for a steady load within $18-24$ hours per day. Hence,

$\mathrm{P}=\frac{W T x V}{C s}$

$=\frac{4231.4 \times 0.509}{1.25}$

Multiplyingp by 1.34 gives the horsepower

$=1723 \times 1.34$

$=2308.86$

$\mathrm{P}=2.3 \mathrm{hp}$

Thus, an electric motor of $2.5 \mathrm{hp}$ is selected for the composting machine.

\subsubsection{Calculation of Gear Torque}

The gear torque is given by

$\mathrm{W}_{\mathrm{T}}=\mathrm{T} /\left(\mathrm{D}_{\mathrm{p}} / 2\right)$

Where,

$\mathrm{T}=$ torque acting on pinion

$\mathrm{D}_{\mathrm{p}}=$ pitch diameter, $162 \mathrm{~mm}$ (calculated)

$\mathrm{WT}=4231.4=\mathrm{T} /\left(\frac{162}{2}\right)$

$4231.4=\frac{T}{81}, \mathrm{~T}=342 \mathrm{Nm}$

\subsubsection{Heat Generated and Power Consumed By the Heater}

An electric heating coil made of Ni-chrome (Nickel and Chromium) is used to heat the inner cylindrical drum where composting takes place, which will require a temperature of $70^{\circ} \mathrm{C}$. This temperature is being monitored and regulated by a thermostat. The amount of heat generated $\mathrm{Q}$, is determined using,

$\mathrm{Q}=\mathrm{MC}(\emptyset 2-\emptyset 1)$

Where,

$\mathrm{M}=$ Mass of heating coil

$\mathrm{C}=$ Specific heat capacity of air $=1.0035 \mathrm{~J} / \mathrm{KgK}=1003.5 \mathrm{~J} / \mathrm{gK}$

$\varnothing 2=$ Final Temperature of heating coil $=70^{\circ} \mathrm{C}(343 \mathrm{~K})$

$\emptyset 1=$ Initial temperature of heating coil $=25^{\circ} \mathrm{C}$ (Room Temp.)

Mass $=$ Density $\mathrm{x}$ Volume of heating coil

Where,

Density of Nickel heating coil $=1.225 \mathrm{~kg} / \mathrm{m} 3$

Diameter of heating coil $=0.2 \mathrm{~m}$

Volume of heating coil $=$ Area $\mathrm{x}$ Thickness Area $(A)=\pi r^{2}=3.142 \times 0.1^{2}$

$=0.03142 \mathrm{~m}^{2}$

Thickness of the plate $=0.005 \mathrm{~m}$

Volume of heating coil $=0.03142 \times 0.005=0.000157 \mathrm{~m}^{3}$

Mass $=1.225 \mathrm{~kg} / \mathrm{m}^{3} \times 0.0001571 \mathrm{~m}^{3}$

$=0.00019245 \mathrm{~kg}$

$=0.1925 \mathrm{~g}$

Heat Generated Q, from equation 3.32

$=0.1925 \mathrm{~g} \times 1003.5 \mathrm{~J} / \mathrm{gK} \times(343-298 \mathrm{k})$

$=8688.3 \mathrm{~J}=8.69 \mathrm{KJ}$

Power consumed $\mathrm{P}$ is the heat generated per hour, which is given by:

$\mathrm{P}=\frac{Q}{T}$

Where $\mathrm{T}=$ Time $($ in seconds $)=3600 \sec ($ For 1 Hour $)$ 
$\mathrm{P}=\frac{8688.3}{3600}$

$=2.4 \mathrm{KW}$

An electric heater with rating $2.0 \mathrm{KW}$ is selected for this work.

\subsubsection{Fan Speed Calculation}

The speed of fan $\mathrm{V}$ is determined using:

$\mathrm{V}=\frac{\pi D N}{60}$

Where,

$\mathrm{D}=$ diameter of fan $=0.1 \mathrm{~m}$

$\mathrm{N}=$ speed of motor in the fan $=180 \mathrm{rpm}$

$\mathrm{V}=(3.142 \times 0.1 \times 180) / 60$

$\mathrm{V}=0.9426 \mathrm{~m} / \mathrm{S}$

\subsubsection{Machine Frame}

The machine frame consists of the following parts: the outer cylinder (composting drum and chamber), the hopper and the heater box

\subsubsection{Outer Cylinder}

The outer layer, which serves as the housing chamber for the composting drum, is also a cylindrical - shaped hollow solid made of mild steel pipe of $\varnothing 400 \mathrm{~mm}$ and a length of $600 \mathrm{~mm}$. it is directly attached to the frame which supports the machine.

It also a thickness of $2 \mathrm{~mm}$. the delivery chute for collecting the end product passes through an opening at its lower end. Its total volume is given by the equation below:

$\mathrm{V}=\pi \mathrm{R}^{2} \mathrm{~L}$

Inner radius $=400 / 2=200 \mathrm{~mm}$

Total length $\mathrm{L}=600 \mathrm{~mm}$

$\mathrm{V}=3.142 \times 200 \times 200=75,398,223.6 \mathrm{~mm}^{3}$

\subsubsection{Design for Hopper}

Slant Height

L1 $=$ Top length of hopper $=240 \mathrm{~mm}$

B1 $=$ Top breadth of hopper $=240 \mathrm{~mm}$

L2 $=$ Bottom Length of hopper $=120 \mathrm{~mm}$

B2 $=$ Bottom breadth of hopper $=120 \mathrm{~mm}$

$\mathrm{H}=$ Height $=200 \mathrm{~mm}$

$\mathrm{S}=$ Slant height

$\varnothing=$ Angle of inclination of hopper

\subsubsection{Volume of Hopper}

The volume of hopper is calculated using:

Volume of hopper, $\mathrm{V}_{h}=\mathrm{V}_{b}-\mathrm{V} s m$

Where $\mathrm{V}_{b}=$ volume of inlet

$\mathrm{V}_{\mathrm{s} m}=$ volume of outlet

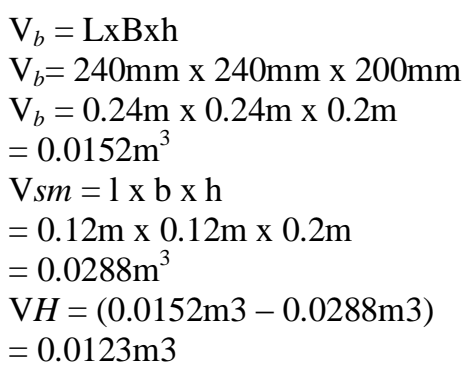

2.3.14 Heating Chamber Design

Volume of heater and fan chamber $=\mathrm{L} \times \mathrm{B} \times \mathrm{h}$

$=215 \mathrm{~mm} \times 180 \mathrm{~mm} \times 130 \mathrm{~mm}$

$=0.215 \mathrm{~m} \times 0.18 \mathrm{~m} \times 0.13 \mathrm{~m}$

$=0.005031 \mathrm{~m}^{3}$

\section{RESULTS AND DISCUSSION}

$26.9865 \%$ demoisturization was achieved within a period of 3hours with varying masses. Normal composting for this same amount of waste using traditional means without a controlled environment, as discussed earlier, will take about 3-4 weeks (about 504-672 hours) to complete the process of composting.

The total output of the wet and dry food waste was obtained and the average value calculated to be $6.67 \mathrm{~kg}$ and $4.87 \mathrm{~kg}$ respectively.

Efficiency of the initial composting machine (Previous) $=$

$\frac{2.45}{4.75} * 100 \%$

Efficiency (Previous) $=51.58 \%$

(Ojumu and Opafunso, 2012)

Hence the efficiency of the machine $($ new $)=$ $\frac{4.87}{6.67} * 100 \%$

Efficiency $(\mathrm{New})=73 \%$ 


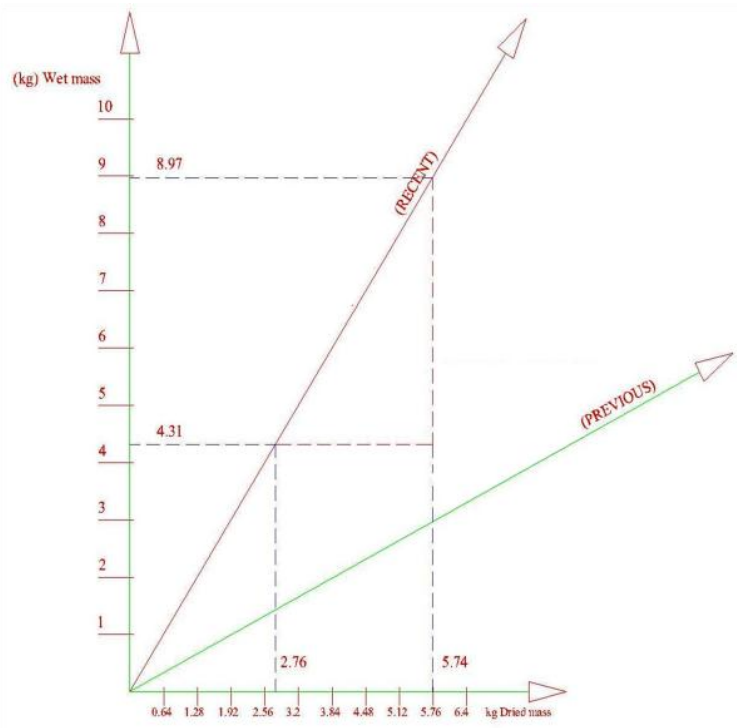

Fig 1: A Comparative Efficiency Graph of the Previous and New Tests

\section{CONCLUSION AND RECOMMENDATIONS}

Based on the design, and fabrication of an effective composting machine for small-scale agricultural processes is achievable using local content materials and indigenous technology. The efficiency of the machine is at a value above average, further research can be carried out to improve the existing design. Furthermore, the design aim and objectives were achieved. The machine can thus be said to have appropriate technology for efficiency in output, and if further research is carried out on the study, the quantity of output and time of operation can be improved upon. With the machine, composting time and cost of purchasing manure will be saved on a long term basis, while agricultural practices and machine fabrications using indigenous technology will be encouraged.

\section{REFERENCES}

[1] Chelecha, O.P. (2003). Design fabrication of a multipurpose composting machine, Vikas Publishing House PVT Ltd, New Delhi.

[2] Ellis, D. (2001) Land Application of Morality Compost to Improve Soil and Water Quality. In Green book 2002: Cropping Systems and Soil Fertility (pp. 30-32). St. Paul, Minnesota: Minnesota Department of Agriculture.

[3] Glanville, T.D. (2001). Design a composter for your facility. Ames, Iowa: Department of Agricultural \&Biosystem Engineering, Iowa State University.

[4] Keener, H.M., Elwell, D.L., \&Monnin, M.J. (2000).Procedures and equations for sizing of structures and windrows for composting animal mortalities. Applied Engineering in Agriculture, 16(6), 681-692

[5] Looper, M. (2002).Whole animal composting of dairy cattle. East Syracuse, New York: Dairy Business Communications.

[6] Martin, J.J. (2000). Engineering Mechanics of Machine, Newirl Publishers, Holland.

[7] Murphy, D.W. and Carr, L.E. (1996). Composting of source separated MSW: An approach to respirometric techniques and biodegradation kinectics. ActaHorticulturae, 546, 81-89

[8] Ojumu, O.M. and Opafunso M. (2012). Report on the development of a household Kitchen waste composting machine, chapter 3, Department of Mechanical Engineering, Federal University of Technology Akure, Ondo State.

[9] Pifeffer, J.T. (1999). Solid waste management engineering, prentice hall, eaglewood cliffs, New Jersey.

[10] Pitchel, J. (2007). Waste management practices on municipal, hazardous and industrial waste CRC press, Florida.

[11] Rhyner, C.R, Schwartz L.J., Wenger R.B. and Kohrell, M.G. (1999).Waste Management and Resource Recovery.Lewis publishers, Florida.

[12] R.SKhurmi and J.K Gupta (2005). Machine Design, Eurasia Publishing House (PVT) Lad, New Delhi-110 055.

[13] Rynk, R (1992),Farm Composting Handbook, NRAES (National Resources, Agricultural and Engineering Services), Co-operative Extension, Ithaca, New Jersey.

[14] Wilson, C.R (2009) Design of a domestic composting machine, Gefrit housing Publishers, Liverpool. 